\title{
GENERAL LINGUISTIC DICTIONARY DESCRIPTIVE STUDY
}

\author{
Omar Hassan RASHID ${ }^{1}$ \\ Waqas Saadi GHARKAN ${ }^{2}$
}

\section{Istanbul / Türkiye \\ p. 454-472}

Received: $14 / 12 / 2021$

Accepted: 20/12/2021

Published: 01/01/2022

This article has been scanned I iThenticat No plagiarism detected

\begin{abstract}
:
The first antecedents in the service of the language of the Holy Qur'an were serious about learning, teaching and compilation. They exerted extraordinary efforts that reflected an organized mentality, sincerity and unparalleled dedication which impressed the whole world. These efforts included the linguistic part of the language, its morphology, phonetics and dictionary, and they have in each aspect fruitful studies and precedent and informed opinions.

There are several aspects that have contributed to the admission of linguistics into modern Arab culture. Of these, sending Arab scholarships to western universities; conducting university studies and thesis by Arab students in European and American universities; establishing a special section in linguistics in some Arab universities; the emergence of linguistic writings known as modern linguistics; the emergence of Arabic translations of some linguistic articles; the organization of local and international scientific seminars and meetings in the field of linguistics; and the establishment of self-list specialties in general linguistics.

However, it is no wonder that others add up to the achievements of the antecedents of theories that deal with linguistic studies, and extract meanings from beyond the linguistic text, all of which is related to the renaissance witnessed by other sciences in the modern era, and which linguists have benefited from in the linguistic field.

Some linguists have collected the terms that have emerged from modern linguistic literature, who have varied in their approaches in arranging these terms. I have chosen five of these general linguistic dictionaries and addressed them in description and analysis, indicating the differences amongst them and what distinguishes each from others.
\end{abstract}

Key words: Linguistics, Culture, Phonetics.

http://dx.doi.org/10.47832/2717-8293.15.33

1 Dr. , Baghdad Education Directorate, Iraq

2 iD Dr. , Imam Azam University College, Iraq, w__87s@icloud.com, https://orcid.org/0000-0001-5538-023X 


\section{المعجم اللسالي العام دراسة وصفية}

\section{عمر حسن رشيد 3 \\ وقاص سعدي غركان}

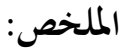

قد جادتُ أقلام الاوائل في خدمة لغة القرآن تعلّما وتعليما وتأليفا، فوردت عنهم جهود متميزة، تنمُّ عن عقلية منظمة، وإخلاص وتفالٍ منقطع النظير أهرت القاصي والداني، وقد شملت هذه الجهود نحو اللغة وصرفها وصوتها ومعجمها، ولمم في كل جانب من هذه الجوانب دراسات مثمرة، وآراء متقدمة وواعية.

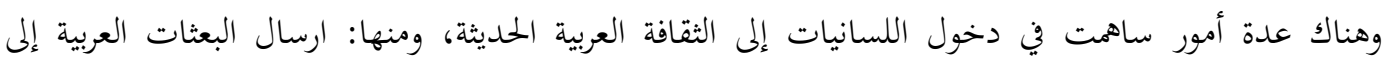
الجامعات الغربية، والقيام بدراسات جامعية واطروحات من قبل طلاب عرب في الجامعات الاوربية والامريكية، وانشاء كرسي خاص بعلم للغة في بعض الجامعات العربية، وظهور كتابات لغوية تعرف بعلم اللغة الحديث، وظهور ترجمة عربية لبعض المقالات اللسانية، وتنظيم ندوات ولقاءات علمية محلية ودولية في بجال اللسانيات، وانشاء تخصصات قائمة الذات في اللسانيات العامة ولكن ليس عجبا أن يزيد الآخرون على ما جاء به الأولون من نظريات تعنى بدراسة اللغة، وتستخرج ما وراء

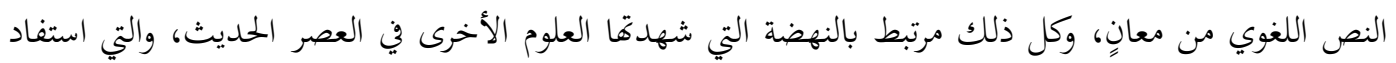
منها المختصون بالمجال اللغوي. وقد هض بعض الباحثين بجمع المصطلحات التي استجدت من المؤلفات اللغوية الحديثة، وهم متباينون في المناهج التي اتبعوها في ترتيب هذه المصطلحات، وقد وقفت على خمسة من هذه المعاجم اللسانية العامة، فتناولتها بالوصف والتحليل مبينًا الفرق بينها وما يميز بعضها على الآخر. الكلمات المفتاحية: اللسانيات، اللغة، المصطلحات.

قد جادتُ أقلام الاوائل في خدمة لغة القرآن تعلّما وتعليما و تأليفا، فوردت عنهم جهود متميزة، تنمُّ عن عقلية منظمة، وإخلاص وتفانٍ منقطع النظير أهرت القاصي والداني، وقد شملت هذه الجهود نحو اللغة وصرفها وصوقا ومعجمها، ولهم في كل جانب من هذه الجوانب دراسات مثمرة، وآراء متقدمة وواعية.

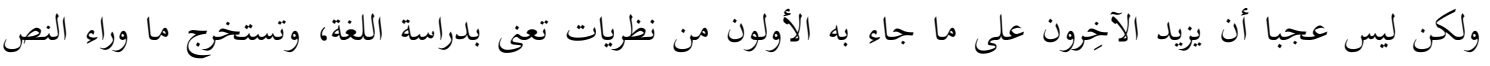
اللغوي من معانٍ، وكل ذلك مرتبط بالنهضة التي شهدما العلوم الأخرى في العصر الحديث، والتي استفاد منها المختصون بالمجال

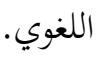


وقد هض بعض الباحثين بجمع المصطلحات التي استجدت من المؤلفات اللغوية الحديثة، وهم متباينون في المناهج التي

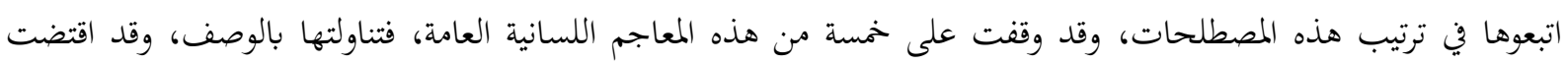
طبيعة المادة أن أسرد المعاجم بشكل متسلسل تسبق الدراسة الوصفية مقدمة وتختمها خاتمة البحث. وجاء المبحث الأول بنظرة تاريخية موجزة في اللسانيات ومعاجمها، واشتمل المبحث الثاني على وصف عامّ للمعاجم، بينما

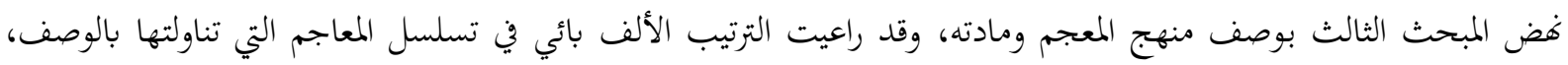
وأعطيت كل معجم رقم، ابتداء برقم (1) وانتهاء بالرقم (5)، وذكرت ما يندرج تحته من تفصيلات عامة، وتفصيلات منهجية. 


\section{المبحث الأول}

\section{نظرة تاريخية في اللسانيات ومعاجمها}

تعدّ اللسانيات من العلوم الحديثة، ويرجع تاريخها إلى القرن التاسع عشر (لأنه شهد ثلاثة منعطفات كبرى في مسيرة هذا

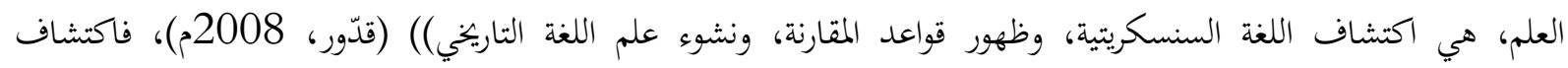

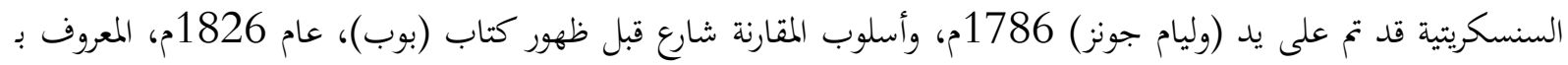
(في نظام تصريف اللغة السنسكريتية ومقارنته بالأنظمة الصرفية المعروفة في اللغات اليونانية واللاتينية والفارسية والجرمانية)، وأبرز مجال عرف أسلوب المقارنة هو علم التشريح وعلم الحياة، واهتم غريم ودييز وشليشر بوضع القواعد التاريخية، ولم يكن الفرق واضحا

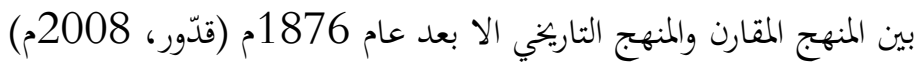

ولم تأخذ اللسانيات في الوطن العربي حقها من العناية في الدرس اللغوي؛ لأن الاعتقاد السائد ((أن مشكل المعطيات

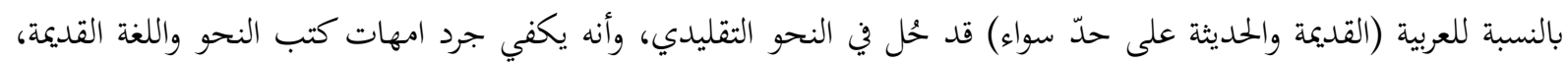

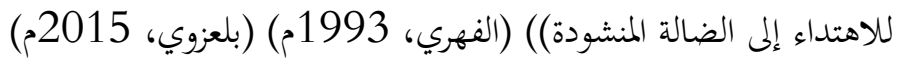

وذهب بعض الدارسين العرب أن اللغة العربية انفردت بخصائص لا توجد في لغات أخرى، وعلى هذا الأساس لا يمكن

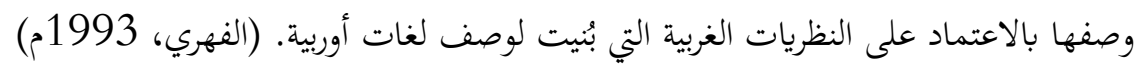
وهناك عدة أمور ساهمت في دخول اللسانيات إلى الثقافة العربية الحديثة، ومنها: ارسال البعثات العربية إلى الجامعات الغربية، والقيام بدراسات جامعية واطروحات من قبل طلاب عرب في الجامعات الاوربية والامريكية، وانشاء كرسي خاص بعلم العاد للغة في بعض الجامعات العربية، وظهور كتابات لغوية تعرف بعلم اللغة الحديث، وظهور ترجمة عربية لبعض المقالات اللسانية، وتنظيم ندوات ولقاءات علمية محلية ودولية في مجال اللسانيات، وانشاء تخصصات قائمة الذات في اللسانيات العامة. (غلفان، $(2006$ ومن أشهر تعريفات المعجم اللساني ما ذكره الدكتور سمير استيتية بقوله: ((هو المصطلح الذي يتداوله اللسانيون، للتعبير عن أفكار ومعاني لسانية، ويمكن أن يكون مظلة بحثية تضم تحت جناحيها أعمالاً علمية تبحث في المصطلحات المبات اللسانية))

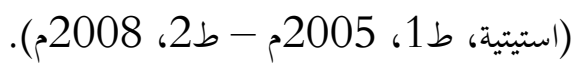

والمقصود بالمعجم العام: هو المعجم الذي يهدف إلى تغطية أكبر عدد ممكن من مفردات اللغة، وهو على العكس من

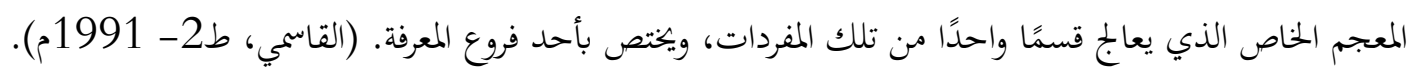
أما أشهر الجهود المعجمية العربية في اللسانيات فقد ذكر سمير ستيتية في بحثه (نو معجم لسان يشامل موحد)، بعضا من هذه الجهود، وهي (ستيتية، 1992م). 1 - نشرت الدكتورة فاطمة محجوب معجما لسانيا في اللغة الانكليزية. بعنوان:(Dictioanry of Linguistics) وقد

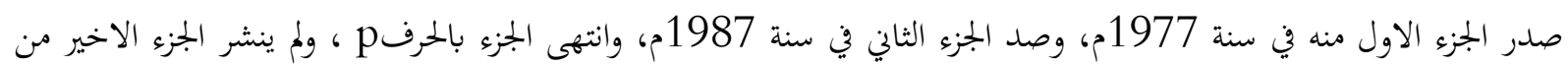

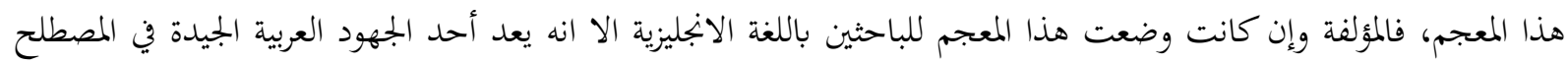
اللساني.

2 - نشر عبد الرسول شاني في الجزء الثاني من المجلد 15، من مجلة اللسان العربي معجما ثنائيا (انكليزي - عربي)، سماه: معجم علوم اللغة، وقد وصل عدد السياقات الاصطلاحية فيه ثمانئة سياق. 
3 - نشر الدكتور محمد علي الخولي في سنة 1982م، معجما من عدة معاجم وضعها، وعنوانه: (معجم علم اللغة النظري)،

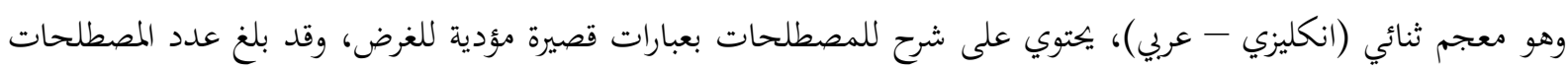
في هذا المعجم زهاء اربعة آلاف وسبعمائة مصطلح.

4 - قام مجموعة من اللغويين العرب بإعداد معجما سمّوه: (معجم مصطلحات علم اللغة الحديث) وقد نشرت دار لبنان في

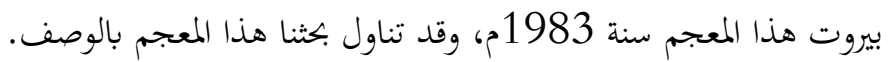
5 - وضع مكتب تنسيق التعريب في الرباط معجما لسانيا ثلاثي اللغة (انجليزي- فرنسي - عربي) في سنة 1984م، وقد جاء هذا المعجم بعنوان: (معجم علم اللسانيات). 6 - نشر الدكتور عبد السلام المسدّي (قاموس اللسانيات) مع مقدمة في علم المصطلح في سنة 1984م، وهو قاموس ثنائي (فرنسي - عربي)، قدم فيه المؤلف أربعة آلاف وثلاثمئة وخمسين مصطلحا فرنسيا، وقدم نظائرها في العربية، دون شرح لمضامينها. 7 - نشر الدكتور بسام بركة في سنة 1985م معجما لسانيا ثنائي اللغة (عربي - فرنسي) سمّاه: (قاموس اللسانية)، وقد ضم هذا المعجم ألفين ومئتي مصطلح. 8 - نشر الدكتور محمد علي الخولي في سنة 1986م، معجمه الثاني، وهو: (معجم علم اللغة التطبيقي)، وهو معجم ثنائي اللغة (انكليزي- عربي)، وهذا المعجم - كما هو واضح من عنوانه- خاص بعلم اللغة التطبيقي. 


\section{المبحث الثاني \\ وصف عام للمعاجم

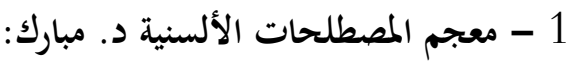 \\ أ. وصف المقدمة:}

لا تتجاوز مقدمة مبارك مبارك صفحة واحدة فقط، شرح فيها الغاية من معجمه، والمنهج الذي اتبعه، وكيفية تعامله مع

بعض العقبات التي اعترضت سبيل ولادة هذا العمل، ولاسيما تلك المترادفات المصطلحية بين العربية ونظائرها (مبارك، ط/1، 1995م)

ب. الغاية والهدف من وضع هذا المعجم:

إن الغاية من هذا العمل تنطلق من الانفتاح للمصطلح العربي على اللغتين الانكليزية والفرنسية، ولا يتوقف هدفه عند

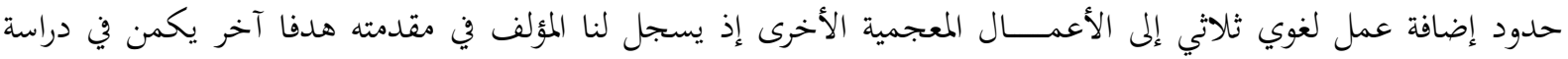
المصطلحات التي تقع تحت تأثير المعطيات الحضارية، فهذه لها أثر في تكوين تعدد للمعنى اللغوي للمصطلح دون أن يكون هناك

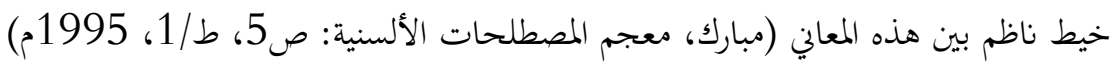

\section{2 - معجم مصطلحات علم اللغة الحديث:}

تأليف نخبة من اللغويين العرب، وهم (د.محمد حسن باكلّا، و د.محيي الدين خليل الرَّّح، و د.جورج نعمة سعد،

ود.محمود اسماعيل صيني، ود.علي القاسمي):

أ. وصف المقدمة:

وقعت مقدمة المعجم في ثمان صفحات، ذُكر فيها الغاية من تأليف المعجم، وجاء في المقدمة الحديث عن طريقة اعداد

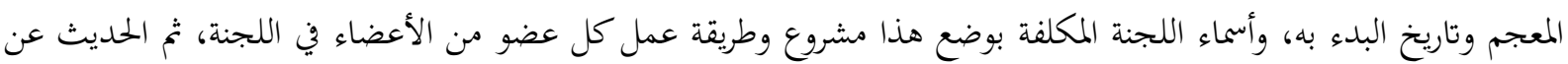

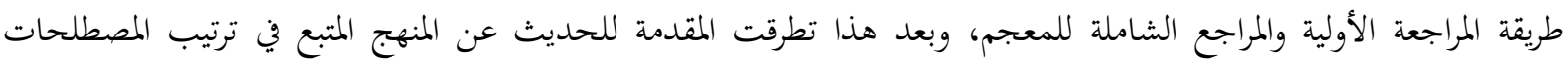

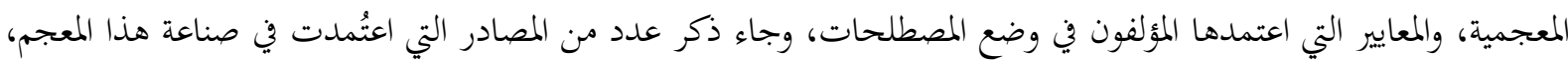

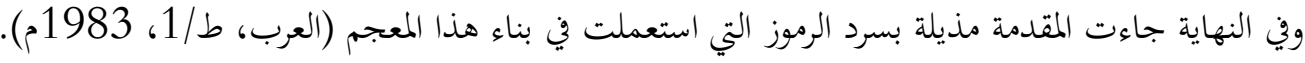

ب. الغاية والمدف من التأليف:

من الملاحظ ان الدراسات اللغوية العربية أصاها الجمود منذ العصور المتأخرة بعد إن ازدهرت في العصور الأولى، وهذا

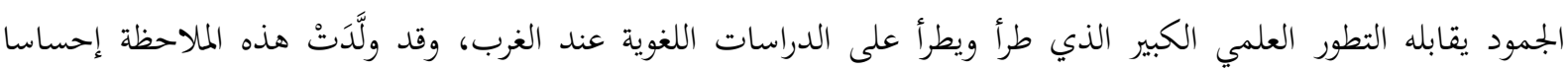

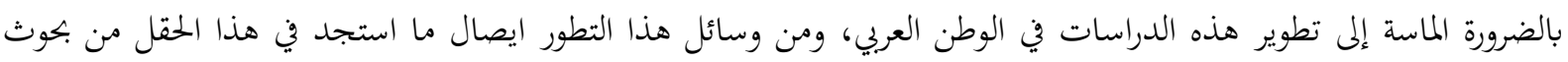

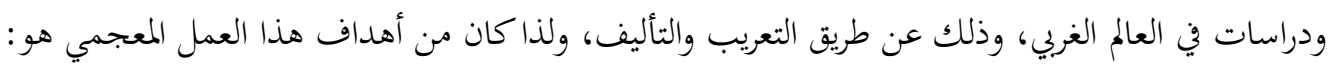
1 - المساهمة في توحيد مصطلحات علم اللغة الحديث على مستوى الوطن العربي.

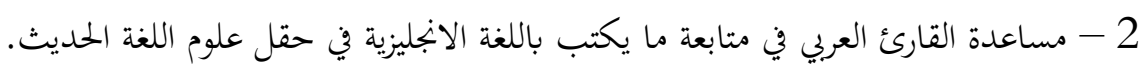
لكن كلا من التعريب والتأليف في حقل الدراسات اللغوية يواجه عقبة كبية وهي مشكلة المصطلحات العلمية لمثل هذا

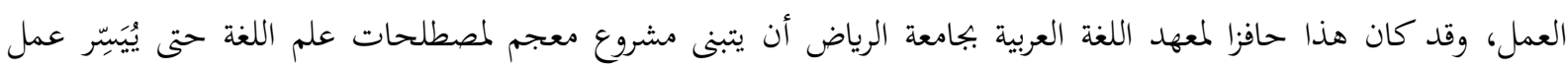

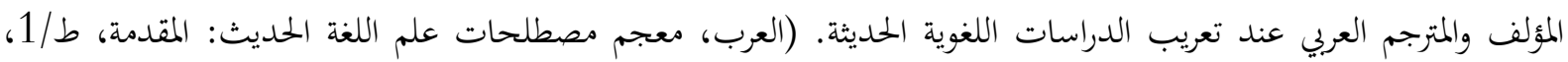




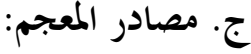

استعان الأعضاء المكلفون بوضع هذا المعجم ببعض المصادر والمسارد في بناء هذا المعجم، ومن هذه المصادر: أ_ مسارد مجمع اللغة العربية بالقاهرة الخاصة بالمصطلحات اللغوية. ب__مسرد معجم علوم اللغة (انجليزي- عربي) للدكتور عبد الرسول شاني، المنشور في مجلة اللسان العربي عام 1977م. جـــ المسارد التي وردت في الكتب الآتية: أولا: دراسة الصوت اللغوي: أحمد مختار عمر. ثانيا: علم اللغة وصناعة المعجم: علي محمد القاسي. ثالثا: علم اللغة: محمود السعران.

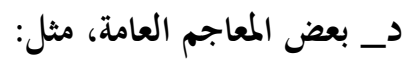
أولا - معجم المصطلحات العلمية والفنية: أحمد شفيق الخطيب. ثانيا - المورد: منير بعلبكي.

3 - معجم المصطلحات اللسانية للدكتور عبد القادر الفاسي الفهري، بمشاركة نادية العمري:

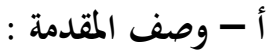

وقعت مقدمة الفاسي في صفحتين، ذكر فيها مصادر معجمه، والمنهج الذي اتبعه في بناء معجمه، وذكر موقفه من المصطلحات العربية القديمة، والمصطلحات الغربية المحيثة، ثم ذكر اسهامات الزملاء من اساتذة وطلبة في ولادة هذا المعجم، ووقف قلمه على الغاية من معجمه تلميحاً لا تصريحاً، وهي جمع المصطلحات التي انتشرت على ألسنة الطلبة والأكاديميين في

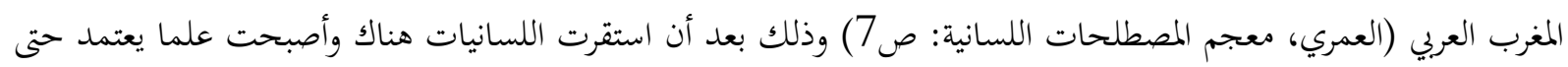

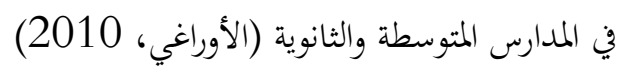
ب - مصادر المعجم: n ذكر المؤلف أن عمله هذا يمثل حصيلة خبرته في البحث والتدريس والتطبيق في الجامعات المغربية، وانه سرت على ألسنة الطلبة مفردات جديدة غالبا ما تكون مضامينها في الأدبيات الغربية، اللاتينية والأنكلوساكسونية والجرمانية، وهذه الروافد التي أمدت العربية ألفاظا ومضامين، أمدت العربية ببناءات تصورية ومعرفية وثقافية مغايرة، وبذلك أعرض المؤلف عن المصادر القديمة،

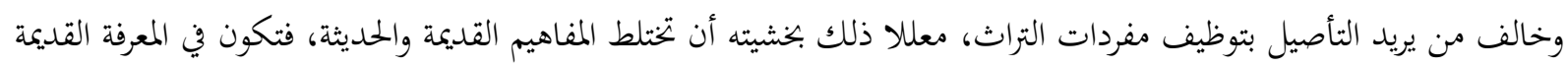
ما لا يوجد فيها، أو تحمّل المعرفة الجديدة تمثُّلات قديمة.

ولميا كانت اللسانيات في المغرب العربي تكلّمت أولا بمفردات المدرسة الوظيفية الفرنسية التي يتزعمها مارتينيه

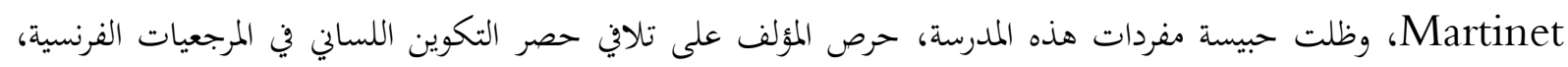
ووسع ذلك من خلال اعتماده ونظره إلى مدارس أخرى من ضمنها النحو التوليدي والتحويلي، والدلالة التصورية أو الصورية،

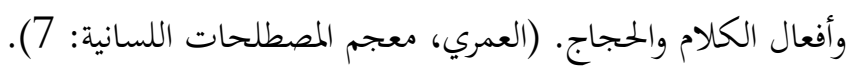




\section{4 - معجم المصطلحات اللغوية الحديثة في اللغة العربية:}

أ - أ - وصف المقدمة:

وقعت مقدمة المعجم في عشر صفحات، ذكر فيها المؤلف الغاية والهدف من هذا المعجم، وموقفه من المصطلحات القديمة، ثم ذكر المصادر التي اعتمدها في معجمه وطريقة اشارته لهذه المصادر، وأهم ما جاء في المقدمة المنهج المتبع في صناعة هذا منها المعجم وطيفية عرض المادة المعجمية (معجم المصطلحات اللغوية الحديثة في اللغة العربية:7 - 16، العدد:4، 1977مهاء 1972م). ب - الغاية والهدف من المعجم:

إن الغاية من هذا المعجم اللساني الحديث هو مواكبة كل جديد في ميادين علم اللغة، ولاسيما في القرن العشرين، فهو كما

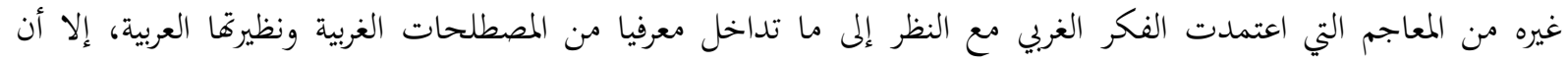
المصطلحات الغربية قد فرضت أصالتها في المجال المعرفي اللغوي مما أرغم العرب على دراستها والتعرف على كنهاتها ؛ كوها مفاتيح

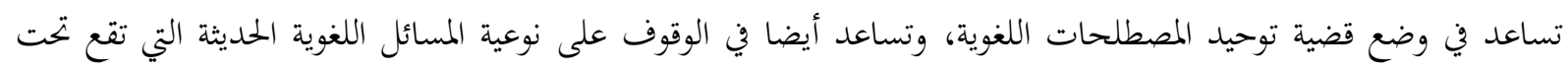

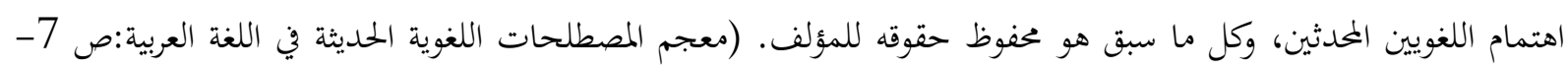

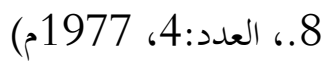
ومما تقدم نجد أن المعجم قد اعتمد على المصادر اللغوية الحديثة التي تناولت بالدرس المسائل اللغوية على ضوء علم اللغة

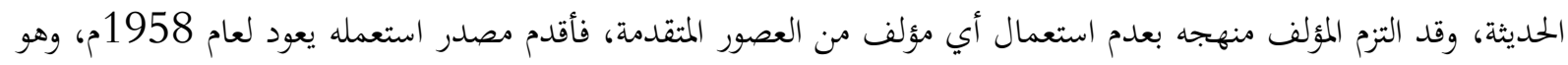

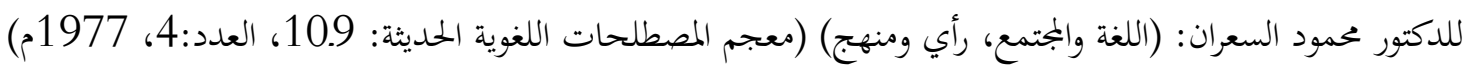
تعامل المعجم مع المصادر في إثباتها نظام الرموز، وهو قائم على ذكر الحرف الأول من اسم المؤلف وأبيه، ومثال ذلك:

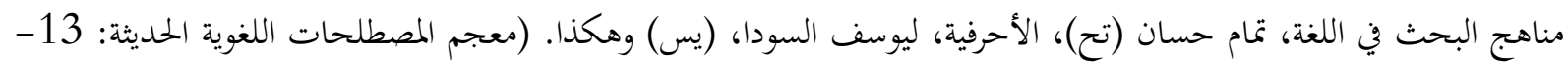

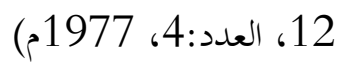

\section{5}

\section{أ - - وصف المقدمة:}

لما كان هذا المعجم موجزا كانت المقدمة موجزة أيضاً، فقد اقتصرها المؤلف في صفحتين، غير أها حوت الأسس والغاية

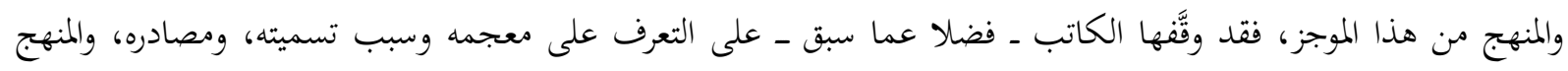
المتبع في بناء عمله. ب - الغاية والمدف من الموجز: قبل الوقوف على الغاية يجب أن نعرف سر تسميته كما يرويها المؤلف: أسميت هذا المسرد موجزا بمصطلح اللغويات،

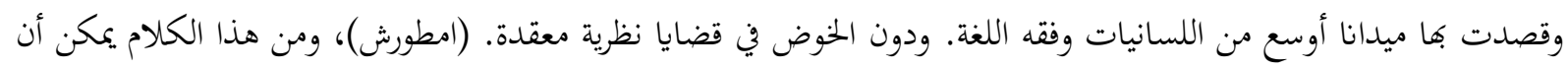

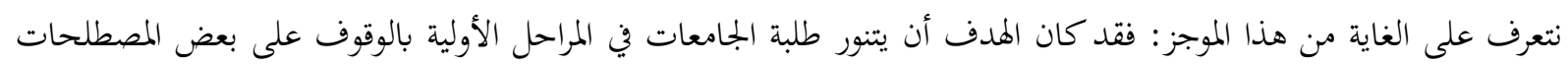

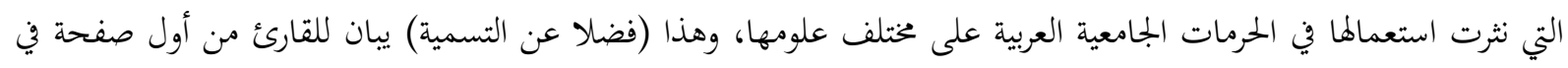

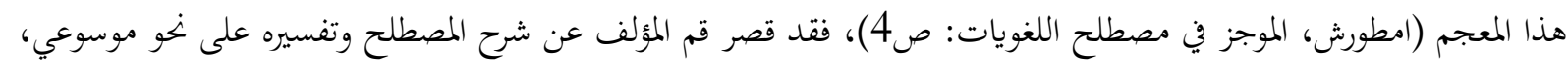
واقتصر على إيراد المصطلح وما يقابله في الانكليزية والفرنسية فقط. 


\section{ج - مصادر الموجز اللساين:}

اعتمد المؤلف في تكوين معجمه على منهج ميداني قائم على التقاط المصطلحات من مجالاتحا المعرفية الموجودة في الكتب

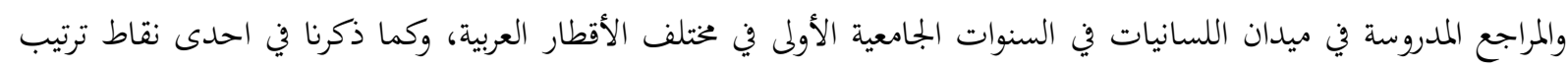

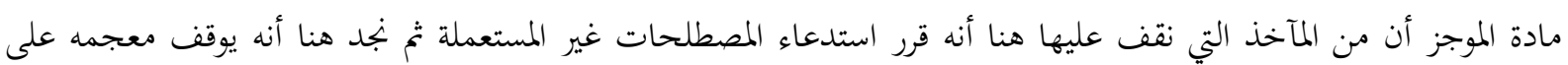

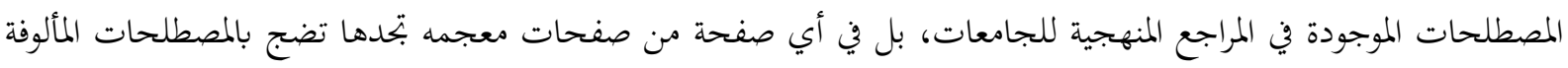
للقارئ، وإن كان لا يعرف كنهها. وكان المصطلح الغربي هو حصيلة الاستعمال الجامعي العربي له، فهذا المصطلح كان منتشرا كذلك في مظان المراجع

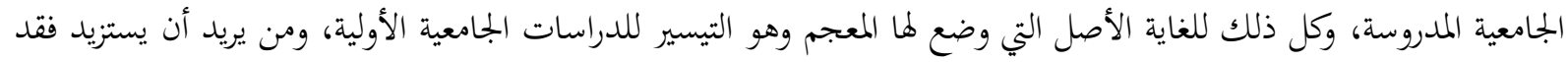

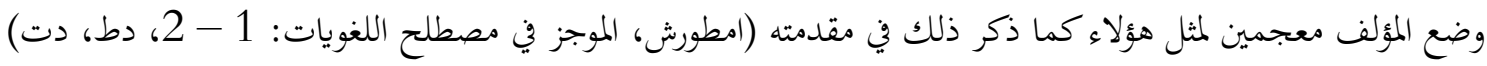


يعد هذا المعجم من المعاجم الثلاثية الوضع ( انكليزي - فرنسي ـ عربي )، لم يعتمد المؤلف أي ترتيب عربي كما هو

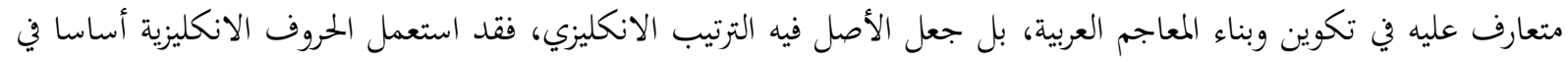

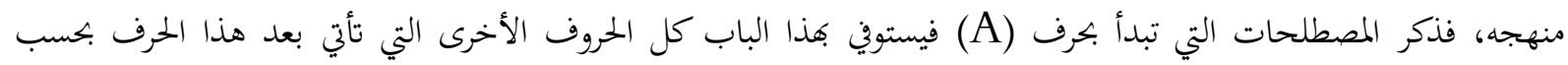

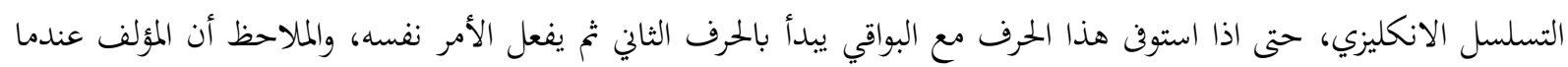
يبدأ بأي حرف فإنه يذكر معه الحروف التي تسبقه في الترتيب الانكليزي.

ب- المادة المعجمية:

الصفة الغالبة على هذا المعجم المصطلح الصوتي وكل ما يحيط به، غير أنه تناول بعض المصطلحات البلاغية واللغوية وغيرها، ولم تقتصر مصطلحاته على بناء مفردي بل تعدى بعض المصطلحات ثلاث كلمات، وبحسب الغاية من ذلك إذ أن الغاية هو زيادة التوضيح لهذه المصطلحات، ومثال ذلك: دراسة الأنظمة الكتابية، التغيير الصائتي الكبير، حركة عالية مصوت عكات عال

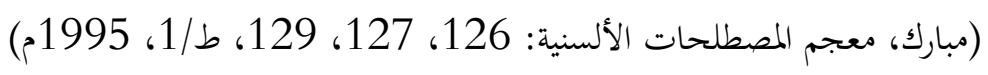

وفي بعض المصطلحات قد يستعمل بعض الروابط الحرفية بينها ولاسيما أحرف العطف، مثال ذلك: مدى ترابطي أو

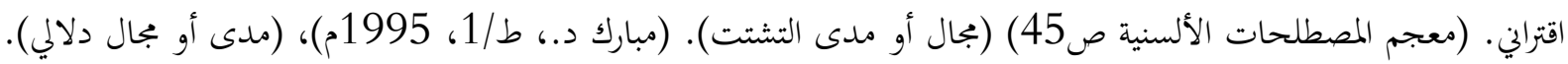

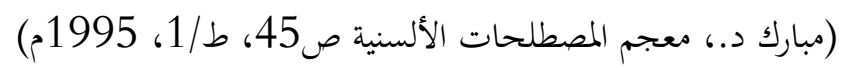

وقد يستعمل الشارحة بين المصطلحات العربية وما يقابلها في الانكليزية، ومن ثوابت العلم أن علامات التنقيط تستعمل بين ثنايا العبارة وليس الكلمة: (المدى الصري - الدلالي) (MORPHO_SEMAN)( (د.مبارك، معجم المصطلحات الألسنية: 46، ط/1، 1995م) استعمل في بعض مداخل المادة المعجمية نظام الإحالة، وقد التزم بأن يحيل السابق للاحق، وقد تكون إحالاته من خاص

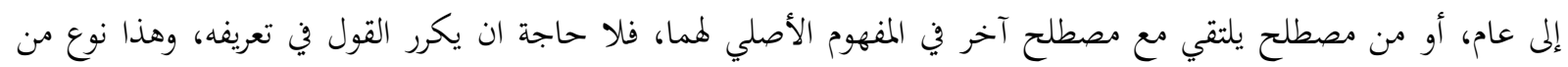

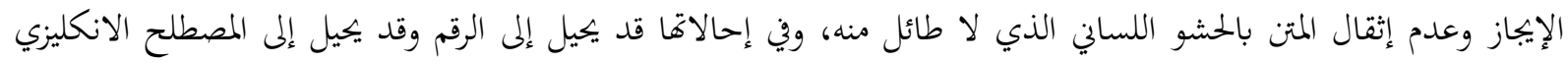
ورقمه، وهذا إن دل على شيء إنما يدل على أصالة المصطلح الغربي عنده، ومثال إحالاته:

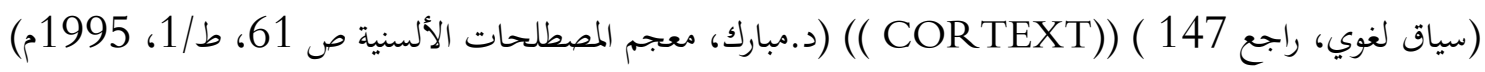
قد يجمع أكثر من مصطلح تحت مفهوم واحد يجمع بينهما ناظم واحد كما ذكر في مقدمته، ومثال ذلك: منسوب إليه،

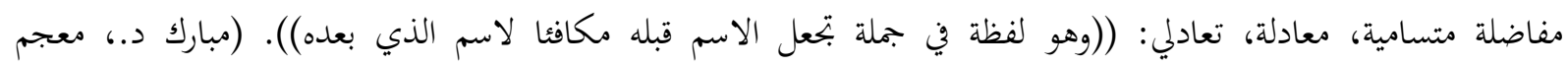
المصطلحات الألسنية ص 99.، ط/1، 1995م) ويلحظ تنوع هذا المصطلح العربي في الانكليزية والفرنسية أيضاً.

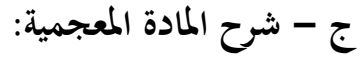

بلغت مداخل هذا المعجم ألفان وتسعمئة وثلاثة وأربعون مدخلا، وعلى عموم هذا العمل لم يثقل المؤلف متن معجمه

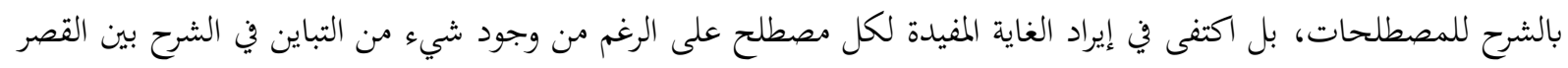


والإطالة إلا أن الفرق بينهما لا يتعدا سطرين أو ثلاثة، وكل ذلك لغاية الفائدة منه، ومثال ذلك: ((وجوب: هو أحد المعاني

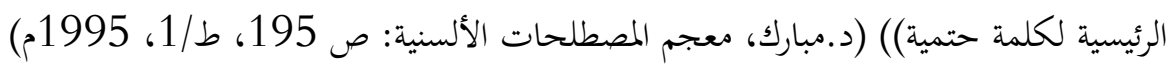

وأما مثال ما أطال في شرحه من مصطلحات: ((أعضاء النطق وهي الاعضاء التي تساهم في عملية النطق، وهي الحنجرة

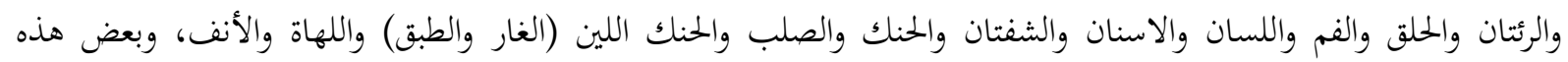

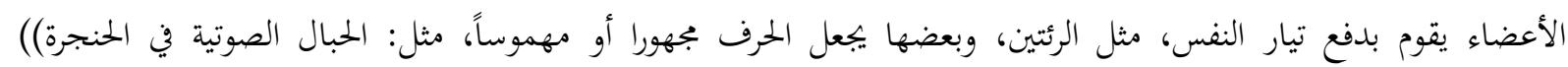

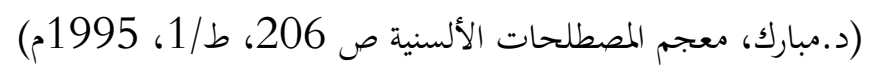

قد يستمل في شرحه للمادة المعجمية بعض الشواهد وإن كان قليلاً في هذا المجال، وهذا ليس مأخذا عليه، وإنما الغاية في

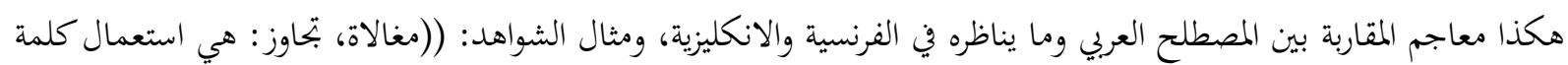

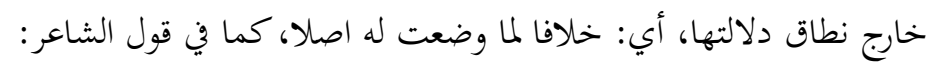

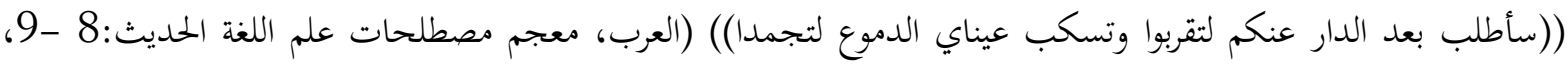
. وقد يكون الشاهد غربيا من أقوال علما الغرب، ((ظرف) أما العالم اللغوي ل. تانيير فقد عرف الظرف بأنه الوحدة أو

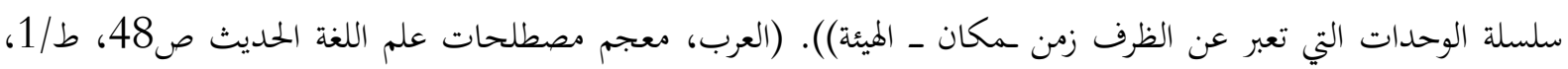

\section{2 - معجم مصطلحات علم اللغة الحديث:} أ - المنهج المعتمد في الترتيب:

يعد معجم مصطلحات علم اللغة الحديث من المعجمات الثنائية (عربي - انكليزي)، سار هذا المعجم في ترتيب مادة

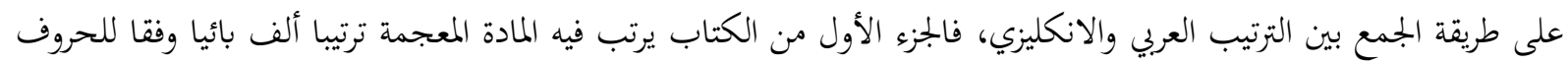

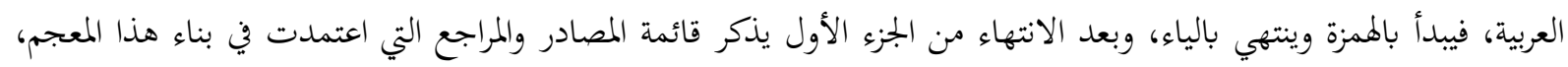

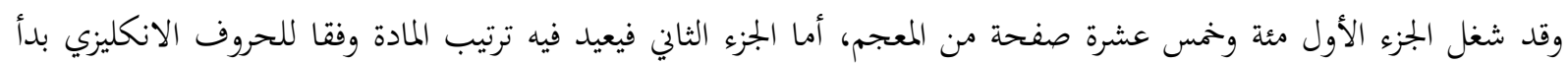

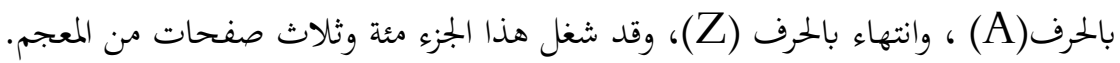
ويلاحظ أن الترتيب الألف بائي لم يأخذ بعين الاعتبار أداة التعريف (ال)، فمثلا (الارتفاع) يأتي قبل (ارتفاع الاسنان)، وعلى هذا يعامل المصطلح المعرّف كمعاملة المصطلح الذي ليس به أداة تعريف. (العرب، معجم مصطلحات علم اللغة الحديث:

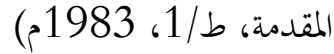

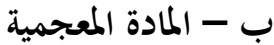
سارت اللجنة المؤلفة لمذا المعجم على عدة معايير في صناعة المادة المعجمية، ومن هذه المعايير (العرب، معجم مصطلحات علم

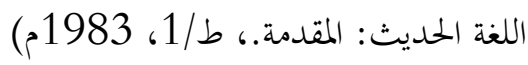
أولا- الاقتصار على مقابلة واحدة لكل معنى من معاني المصطلح الانجليزي ما أمكن ذلك. ثانيا - إعطاء الاولوية للمصطلحات العربية المعروفة قديمها وحديثها، وذلك نحو:

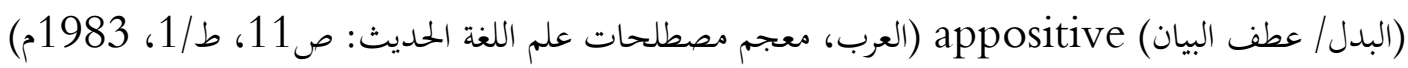
(الخبر في النحو) comment (العرب، معجم مصطلحات علم اللغة الحديث: ص35، ط/1، 1983م) 


$$
\text { ثالثا - صوغ مصطلحات جديدة عند الضرورة، وذلك نحو: }
$$

التبير (accentuation)(العرب، معجم مصطلحات علم اللغة الحديث ص24، ط/1، 1983م) رابعا - تعريب المصطلح الانكليزي في حال غياب مقابل عربي دقيق ومناسب له مع شرح موجز لذلك المصطلح، وذلك نحو: الأكوستي acoustic

(يتعلق بالصوت من حيث موجاته المنتشرة بالهواء) (العرب، معجم مصطلحات علم اللغة الحديث: 7.، ط/1، 1983م) خامسا - استبعاد المصطلحات المهجورة وكذلك اسماء اللغات. سادسا - الاطراد والاتساق في استعمال المصطلحات العربية مع مقابلاتما الانكليزية.

أما علامات الترقيم فِإنه استخدم العلامات الآتية. (العرب، معجم مصطلحات علم اللغة الحديث: المقدمة.، ط/1، (1983

أولا - القوسان الهلاليان: ويشيران إلى ان ما بداخلها هو شرح موجز للمصطلح، أو مرادف له، وذلك نحو: الإبداع ((اللغوي)) creativity العرب، معجم مصطلحات علم اللغة الحديث: ص1، ط/1، 1983م) (الدال على فكرة او شيء)( significant (العرب، معجم مصطلحات علم اللغة الحديث: ص37، ط/1، 1983م) ثانيا - الخط المائل: يشير إلى ان ما بعده بديل للمصطلح الأساسي، وذلك نهو: (الطبق / الحنك اللين) soft palate العرب، معجم مصطلحات علم اللغة الحديث: 57، ط/1، 1983م) (العالمي / العمومي) universal العرب، معجم مصطلحات علم اللغة الحديث: 61، ط/1، 1983م) ثالثا - الأرقام (1 - 2 - 3..(: وتشير إلى المعاني المختلفة للمصطلح الواحد، وذلك نحو: 1 - (بداية المقطع) onset :العرب، معجم مصطلحات علم اللغة الحديث ص11، ط/11، 1983م) 2

\section{3 - معجم المصطلحات اللسانية: أ - المنهج المعتمد في الترتيب :}

يعد هذا المعجم من المعاجم الثلاثية الوضع (انكليزي - فرنسي ـ عربي)، لم يعتمد المؤلف الترتيب عربي كما هو متعارف

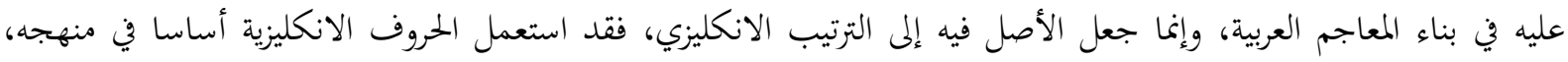

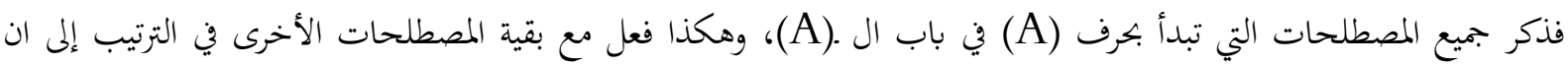
انتهى بالحرف (Z)، وعلل سبب اعتماده الترتيب الانكليزي بأن هذه اللغة نشأت بها في أصل الوضع كثير من المصطلحات بعديه

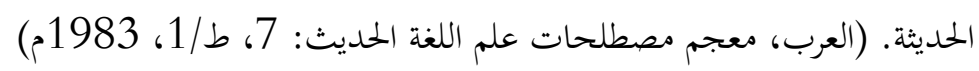
يبدأ ترقيم المعجم من اليسار كما هو معروف في اللغة الانكليزية، وينتهي برقم (406)، ومن جهة اليمين يبدأ ترقيم جديد وينتهي برقم (64)، ويذكر في فاية المعجم من جهة اليمين فهارس بالعربية والانكليزية والفرنسية، ورتب المصطلحات العربية في مهري الفهرس وفق الحروف الالفبائية ويذكر أمام كل مصطلح رقم الصفحة التي وقع فيها، وهكذا فعل مع المصطلحات الانكليزي 
والفرنسية، فرتب الانكليزية وفق الترتيب الانكليزي للحروف، ورتب المصطلحات الفرنسية وفق الترتيب الفرنسي للحروف، وقد

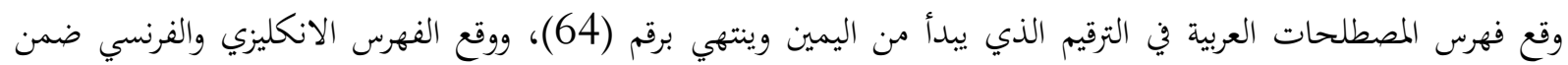

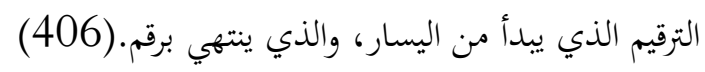

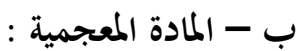

هذا المعجم من المعجمات الثلاثية التي تورد المصطلح الانكليزي كما أسلفنا، وترتب على أساسه، ثم تثبت ما يقابله بالفرنسية والعربية، وذكر المؤلف أن منهجه امتاز بالجرأة في وضع المصطلحات، إذ إنه لم يتبع طرقا مألوفة في ايجاد الألفاظ

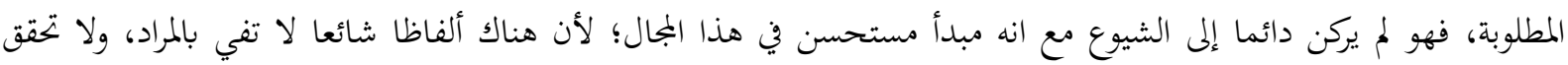
المقصود، وذكر أنه توخى النسقية في وضع المقابلات التي تتعارض مع مبدأ الشيوع، ولجأ إلى كثير من المولدات الجديدة؛ لأن كثيرا من المصطلحات الغربية لم يسبق أن نقلت إلى العربية، وانفرد المؤلف في ذلك في كثير من الاحيان (العمري، معجم المصطلحات

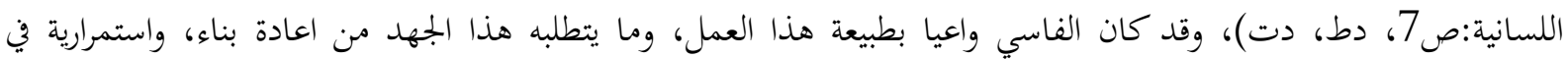

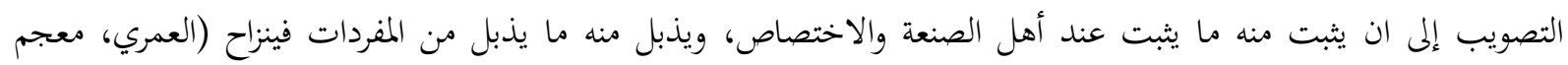
(المصطلحات اللسانية:ص).

ولم يصرح المؤلف في عدد المصطلحات التي ضمها معجمه، ولم يعمد إلى ترقيمها مما يجعل معرفة عدد مصطلحاته امرا عسيرا، وقد تباينت طريقة المؤلف في عرض المصطلح فقد يضع شارحة قبل المصطلح ومرة يستغني عن الشارحة، فمثال ما وضع

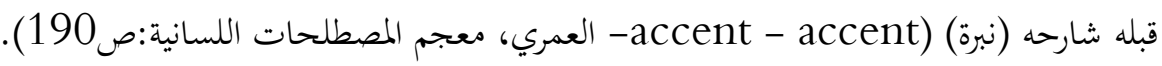
(ومثال ما لم يضع قبله شارحة :حَدْس1intuition intuition (العمري، معجم المصطلحات اللسانية ص 15) وقد يضع شارحة أمام المصطلح الانكليزي دون ما يقابله في العربي والفرنسي، ومثال ذلك: (صوت مقحم. SON)

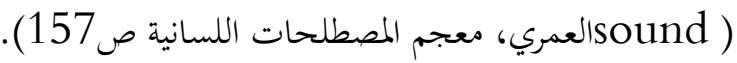

وإذا كان المصطلح الانكليزي يقابله أكثر من مصطلح في العربية، فإنه يذكرها ويفرق بينها بفاصلة، وذلك نحو( :مَزْمَن، فيه زمن) (العمري، معجم المصطلحات اللسانية (334).

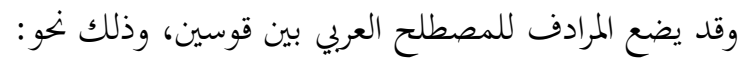
(معجم (قاموس)) (dictionnaire - dictionary) (العمري، معجم المصطلحات اللسانية:327) ويسير المؤلف في معجمه ( كما هو واضح من خلال الامثلة السابق ) على طريقة عرض المصطلح الانكليزي وما يقابله بالفرنسية والعربية، دون أن يشرح المصطلح أو يوضحه.

\section{4 أ- المنهج المعتمد في الترتيب المعجمي:}

اعتمد المؤلف النظام الألف بائي في مداخل المعجم، وهذا بين من ثنايا الفهرست والمادة المعجمية. (معجم المصطلحات

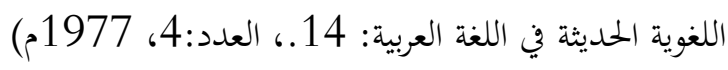

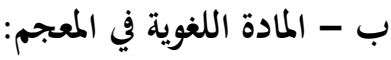

ضم هذا المعجم ألف ومئتين وواحد من المصطلحات، وعلى الرغم من تنوع هذه المصطلحات بين جديدها وقديما إلا أن

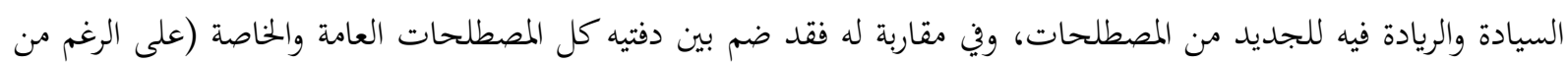


قدم بعضها) التي لم يسبق استعمالها من قبل في العربية، في حين أن القديم منها شرط استعمالها في هذا المعجم أن ترتدي ثوبا

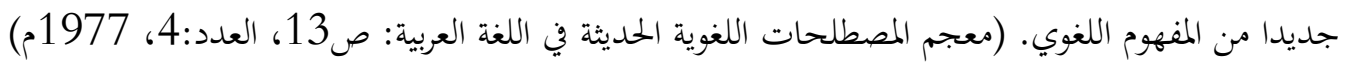
ولم يركز في مادته على المصطلحات التي اشترك العرب في ترجمتها على اعتبار الاتفاق أو المخالفة، بل جمع ما كان مشتركا

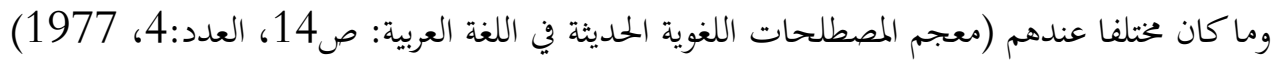
وهذا المعجم ثلاثي التكوين في غالبه، عربي ـ انكليزي ـ فرنسي، غير أنه في بعض الأحايين قد يقدم المؤلف إلى تثبيت

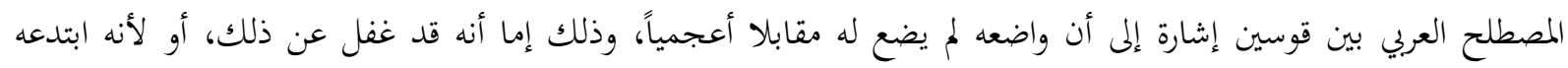

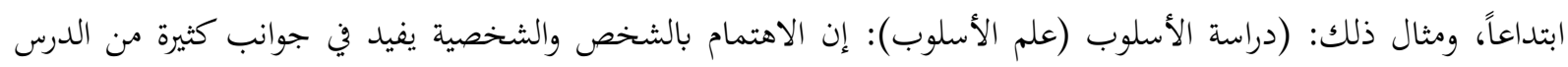

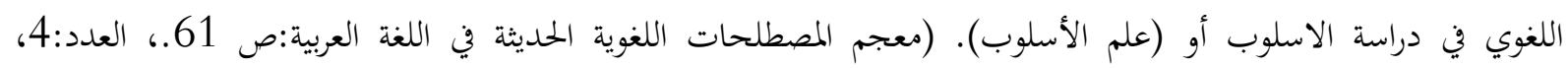
1977م ) وقد يعمد المؤلف بترك فراغ في المكان المقابل الأعجمي خشية اللبس والغموض لإنمان لاسيما إذا كان المصطلح المذكور غير واضح تماماً:

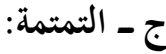

وقد تكون (اللازمة اللغوية) عيباً عضوياً في النطق كاللثغة أو الفأفأة أو التمتمة، وقد تكون أمرا آخر يكفي سماعه أو ذكره

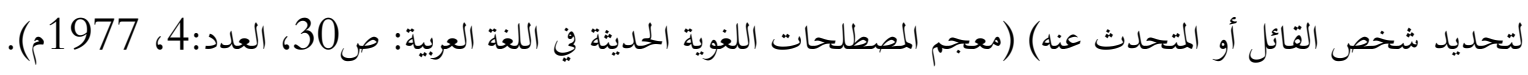
ولم يلتزم المؤلف منهجية واحدة في شرح المادة العلمية فقد يطيل في تبيان مصطلح، وقد يقصر في آخر وكل ذلك بحسب

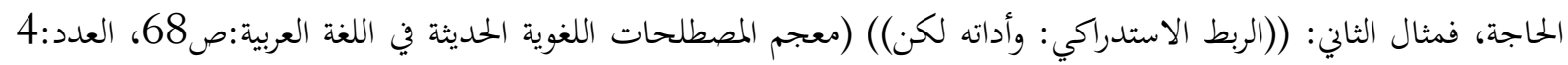

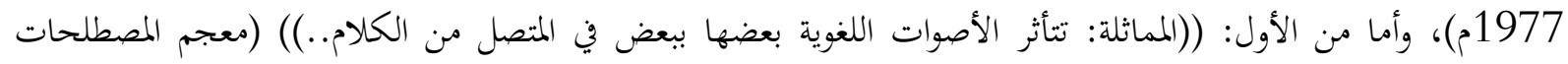

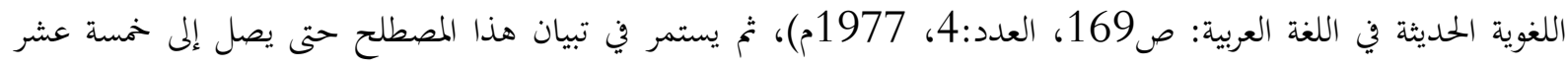
سطرًا.

وقد يعمد في بعض المصطلحات إلى منهج الإحالة عندما تتشابه المصطلحات أو تتقارب على نحو كبير في المعنى، وهو لا

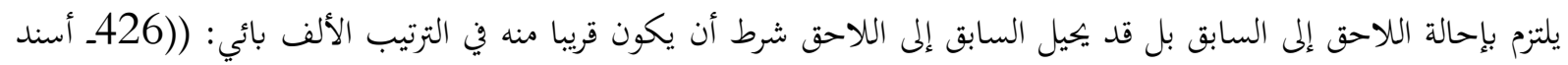

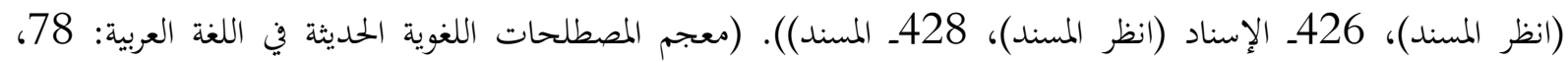
العدد:4، 1977م).

5 - الموجز في مصطلح اللغويات: أ - ترتيب المادة المعجمية:

الموجز من المعجمات الثلاثية البناء (عربي، انكليزي، فرنسي)، لم يزيغ المؤلف عن الأسس التي وضعها في مقدمة معجمه

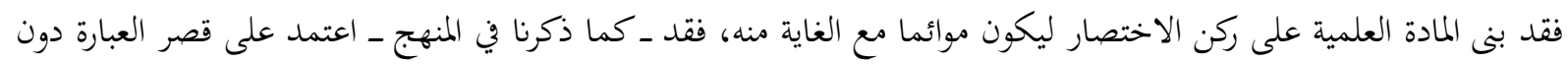

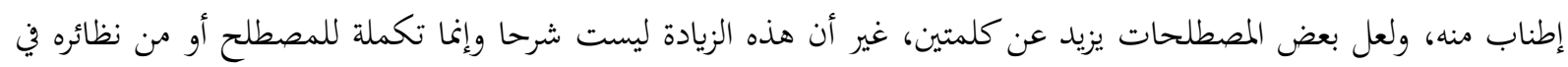

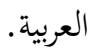

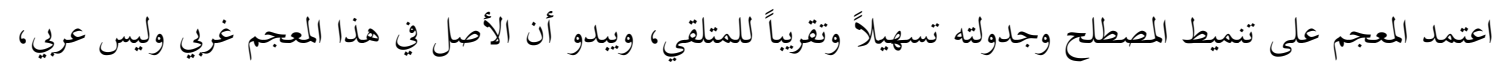

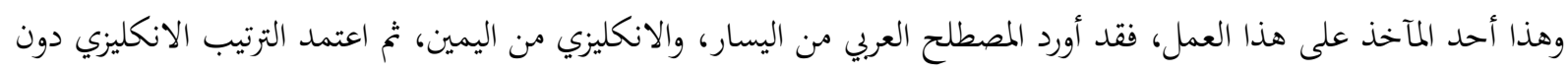


أي مراعاة للعربي، وهذا معجم للنشى العربي، فكيف يمكن أن يقف أحدهم وحتى المتخصص على المصطلح المراد وهو غير مرتب، فصعوبة البحث فيه واضحة للعيان، ولا يبدو سببا مقنعا دفع المؤلف إلى ذلك إلا التشبه والتعبد للموائد اللسانية الغربية. وابتعد عن المصطلح المستعمل ولو كان تراثيا مشهوراً، وهذا أمر غريب يتعارض مع مصادر المعجم كما سنرى. لم يطل الوقوف على إشكاليات المصطلح العربي، فقد خلا من تعدد الاستعمالات، وما يرافقها من ابتكار مصطلحات أخرى، والهدف من ذلك في رأي المؤلف عدم الاستقرار في المصطلح العربي، وابتعاده عن التوحد تحت مظلة المجالات اللغوية. (امطورش، الموجز في مصطلح اللغويات:1 - 1 - 2). ابتعد عن الجمل التفسيرية الكثيرة الاستعمال في الكتابات العربية، فالمصطلح عنده جملة لا تتجاوز ثلاث كلمات في

استدعى بعض الوسائل التوضيحية والتفسيرية التي تمدف أيضا إلى الوقوف على تنويع المجالات التي يستعمل فيها

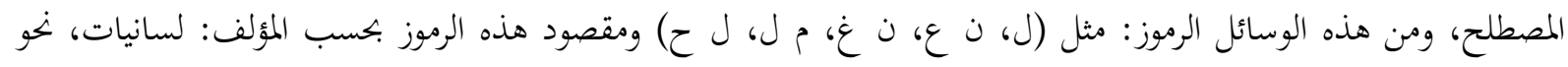

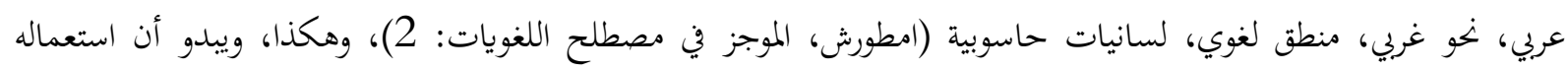

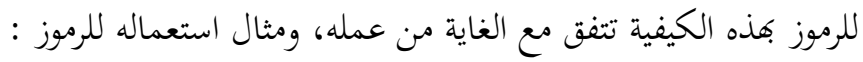

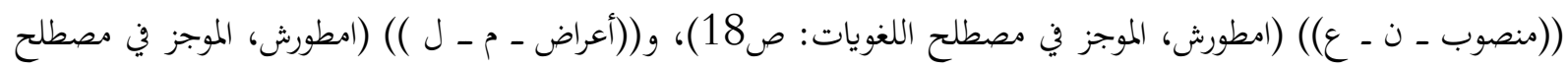

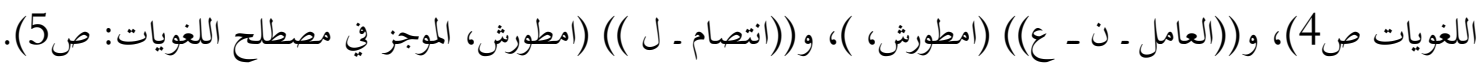
قد يستعمل المؤلف الشارحة في بعض المصطلحات ولاسيما التي ترتبط فيما بينها بخيط تضارعي دقيق، مثال ذلك: ((زائد/ ملحق/ لحاق )) (امطورش، الموجز في مصطلح اللغويات صنات 14)، ((معنى عادي/ إدراج)) (امطورش، الموجز في مصطلح

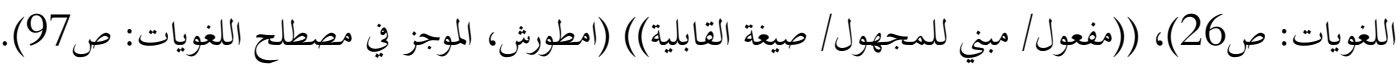

بعد الانتهاء من هذا البحث الوجيز بحمد الله توفيقه آن لي أن أدون اهم ما نتج عنه من نتائج:

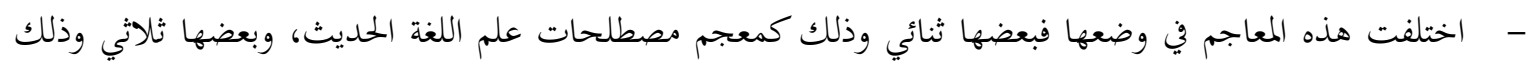

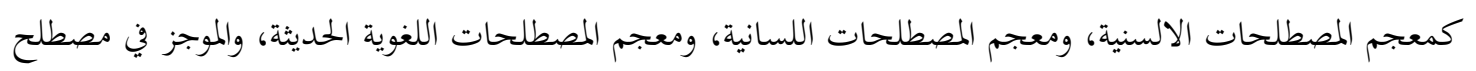
اللغويات. - - بعض المعاجم اللسانية يعتمد الأحرف العربية في ترتيب المادة المعجمية وذلك كمعجم المصطلحات اللغوية الحديثة، وبعضها يرتب المادة وفقا للأحرف الانكليزية وذلك كمعجم المصطلحات الألسنية، ومعجم المصطلحات اللسانية، والموجز في مصطلح اللغويات، وبعضها يجمع بين الطريقتين في الترتيب وذلك كمعجم مصطلحات علم اللغة الحديث.

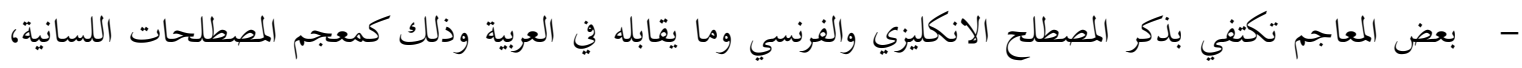

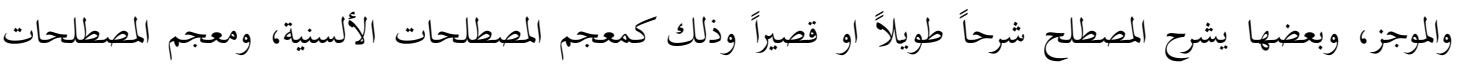

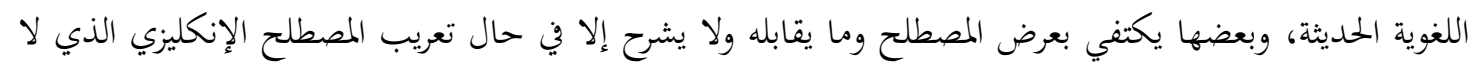
مقابل له في العربية وذلك كمعجم مصطلحات علم اللغة الحديث. - ق قد تمتم بعض المعاجم بإيراد الشواهد في شرح المصطلح اللساني كما جاء ذلك في معجم المصطلحات الألسنية. 
- - أعطت بعض المعاجم الأولوية للمصطلحات العربية قديمها وحديثها؛ وذلك كمعجم مصطلحات علم اللغة الحديث، وذهبت بعض المعاجم إلى تفضيل المصطلحات المولدة كما هو الحال في معجم المصطلحات اللسانية، ومعجم المصطلحات اللغوية الحديثة في اللغة العربية، والموجز. - - استعملت المعاجم اللسانية بعض علامات الترقيم كوسيلة لتنظيم المادة المعجمية. 
د. أممد محمد قدّور. (2008م). مبادئ اللسانيات، ص 17. دمشق: دار الفكر، ط/2008).

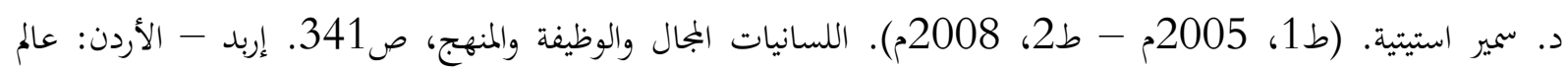

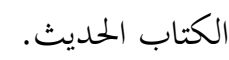

د. عبد القادر الفاسي الفهري. ( 1993م). اللسانيات واللغة العربية نماذج تركيبية ودلالية، ص53-54. المغرب: دار توبقال

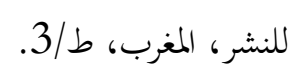

د. عبد القادر الفاسي بمشاركة د. نادية العمري. (بلا تاريخ). معجم المصطلحات اللسانية ص 157. دار الكتاب الجديد المتحدة.

د. عبد القادر الفاسي بمشاركة د. نادية العمري. (بلا تاريخ). معجم المصطلحات اللسانية ص157. دار الكتاب الجديد المتحدة.

د. عبد القادر الفاسي بمشاركة د. نادية العمري. (بلا تاريخ). معجم المصطلحات اللسانية: 7. دار الكتاب الجديد المتحدة.

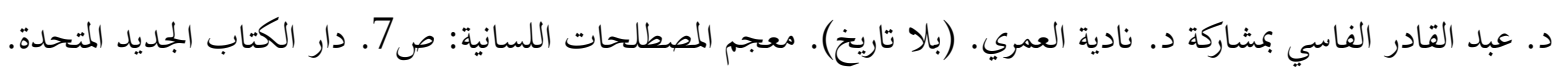

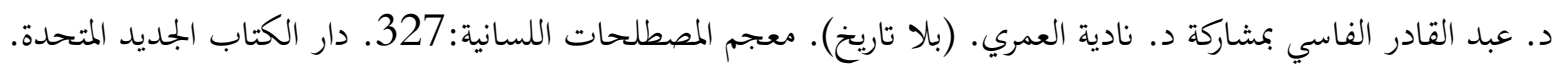

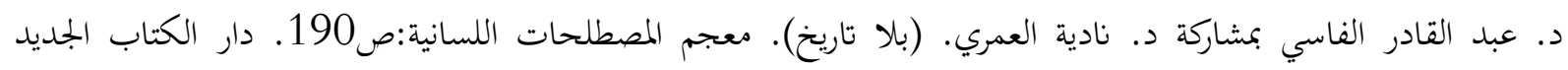
المتحدة.

د. عبد القادر الفاسي بمشاركة د. نادية العمري. (بلا تاريخ). معجم المصطلحات اللسانية:ص7، دط، دت. دار الكتاب الجديد المتحدة.

د. عبد القادر الفاسي بمشاركة د. نادية العمري. (بلا تاريخ). معجم المصطلحات اللسانية:ص8 8. دار الكتاب الجديد المتحدة.

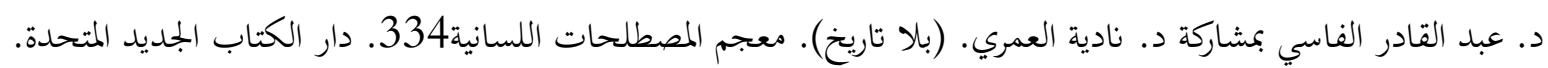

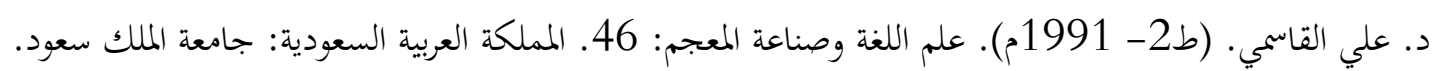

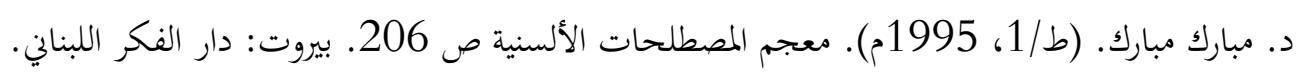

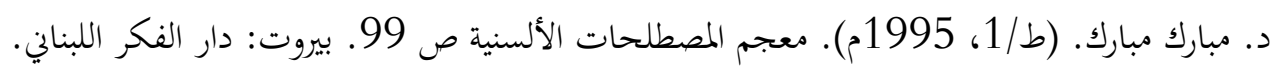

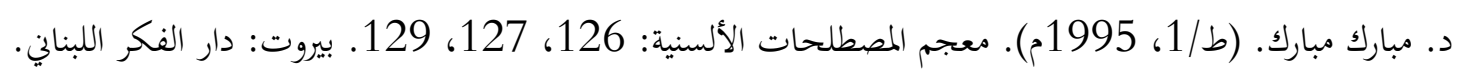

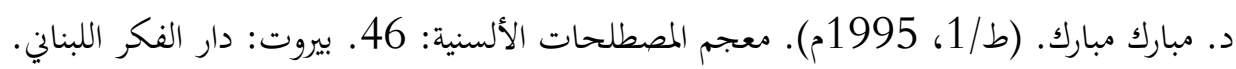

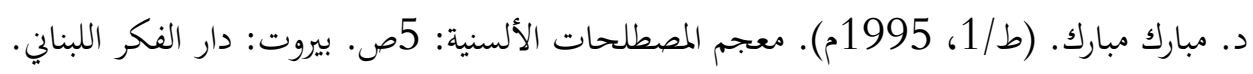

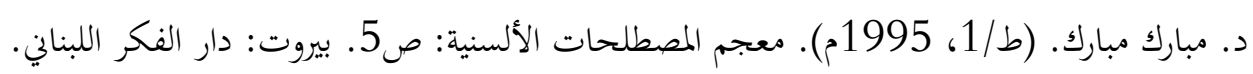

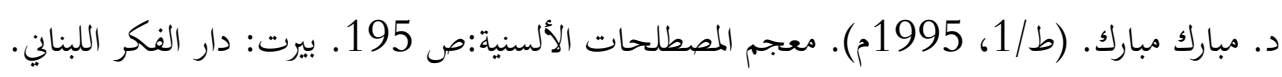

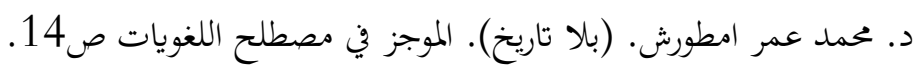

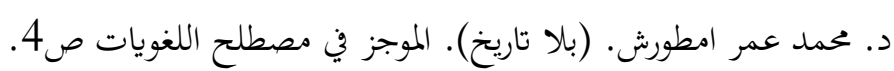

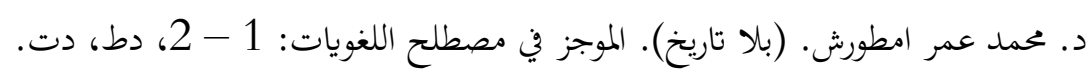

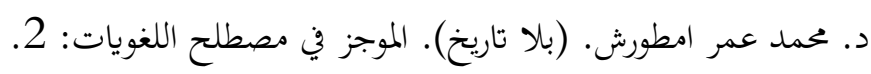

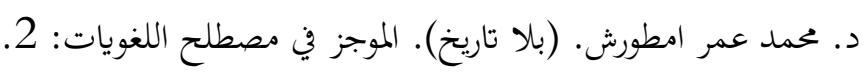

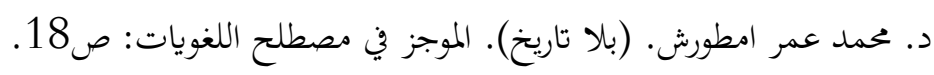

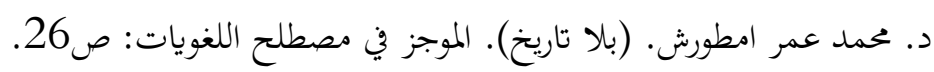


د. محمد عمر امطورش. (بلا تاريخ). الموجز في مصطلح اللغويات: صبات.

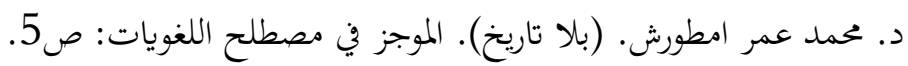

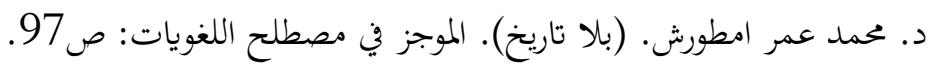

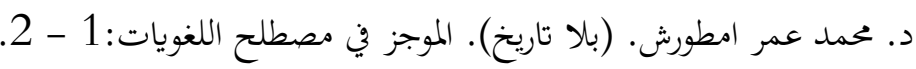

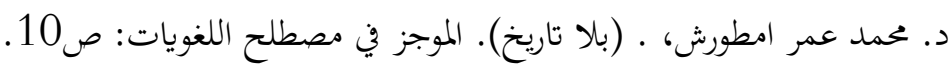

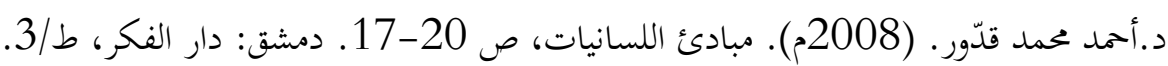

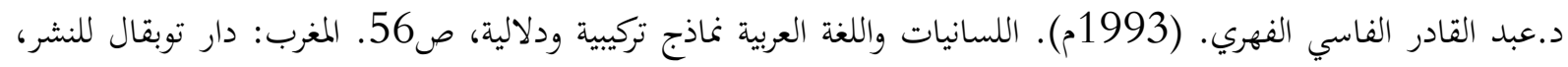
. $3 / 6$

د.مبارك مبارك. (ط/1/3، 1995م). معجم المصطلحات الألسنية ص 6195. بـ بيروت: دار الفكر اللبناني.

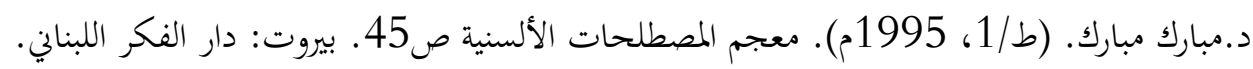

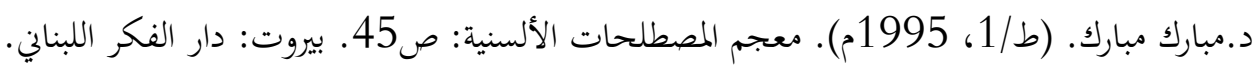

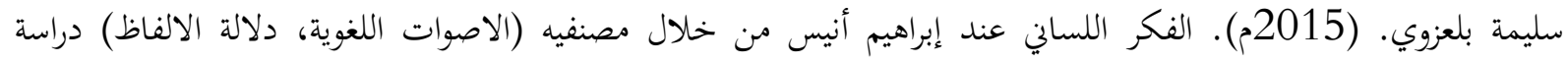

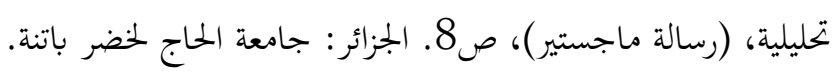

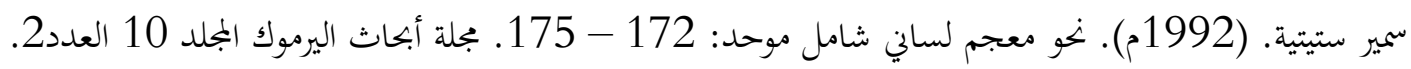

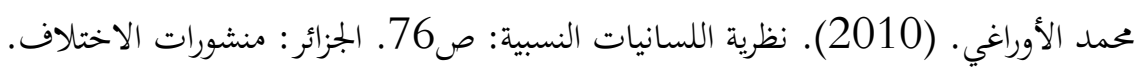

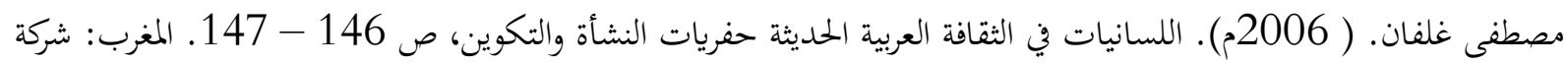

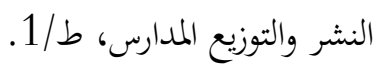

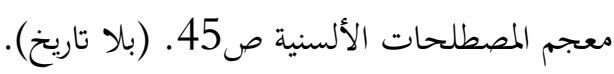

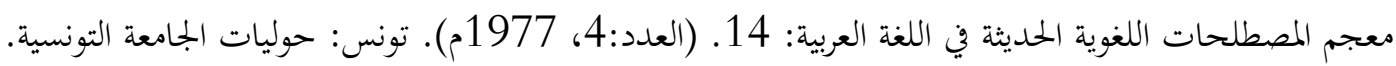

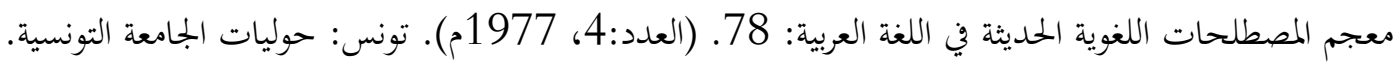

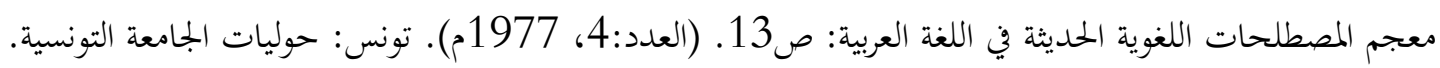

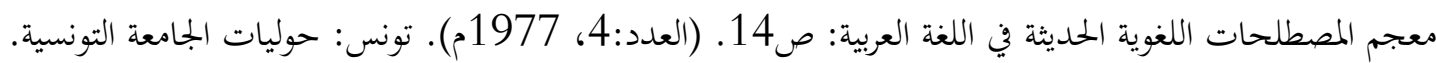

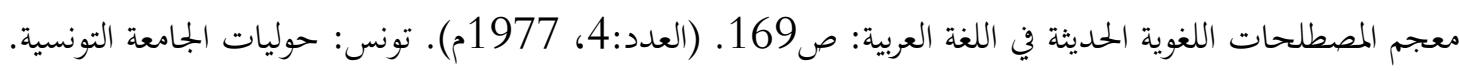

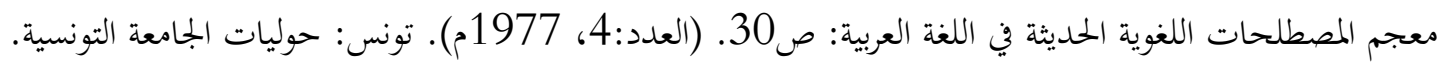

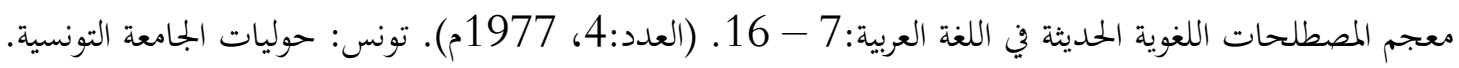

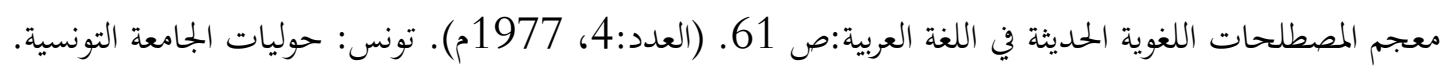

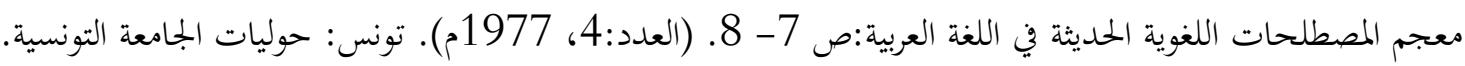

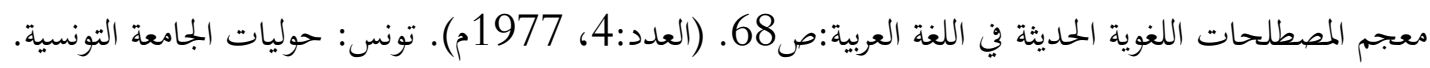

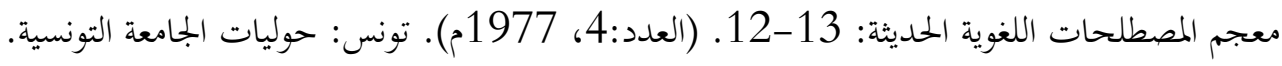

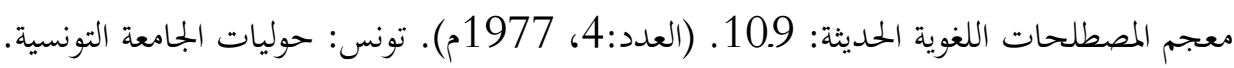

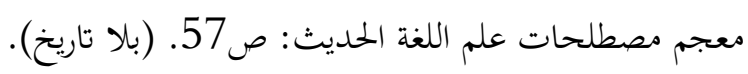
معجم مصطلحات علم اللغة الحديث:. (n.d).

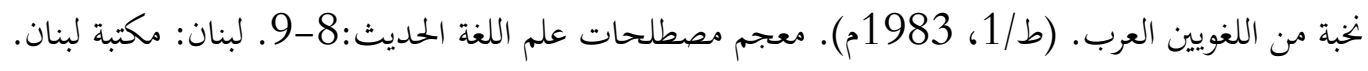

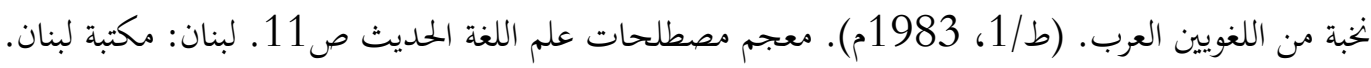


نخبة من اللغويين العرب. (ط/1، 1983م). معجم مصطلحات علم اللغة الحديث ص24. لبنان: مكتبة لبنان.

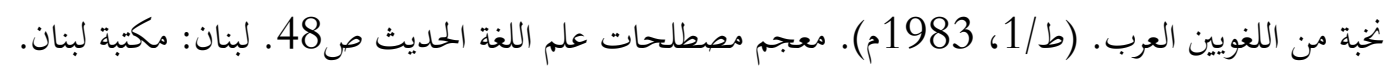
نخبة من اللغويين العرب. (ط/1/، 1983م). معجم مصطلحات علم اللغة الحديث: 57. 57 لبنان: مكتبة لبنان.

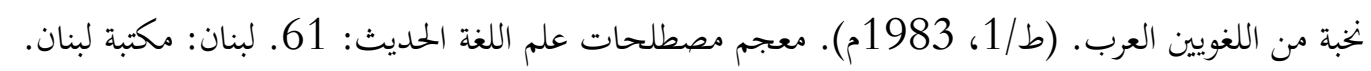
نخبة من اللغويين العرب. (ط/1/، من 1983م). معجم مصطلحات علم اللغة الحديث: 7. 7.

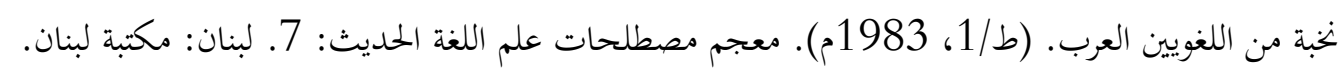

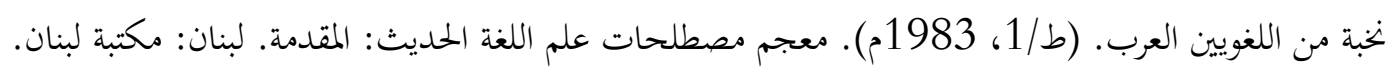
نخبة من اللغويين العرب. (ط/1/، 1983م). معجم مصطلحات علم اللغة الحديث: المقدمة. لبنان: مكتبة لبنان، لبنان. نخبة من اللغويين العرب. (ط/1)، 1983م). معجم مصطلحات علم اللغة الحديث: المقدمة. لبنان: مكتبة لبنان.

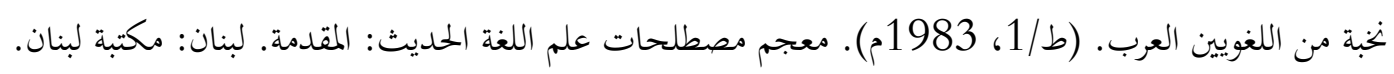
نخبة من اللغويين العرب. (ط/1، 1983م). معجم مصطلحات علم اللغة الحديث: المقدمة. لبنان: مكتبة لبنان.

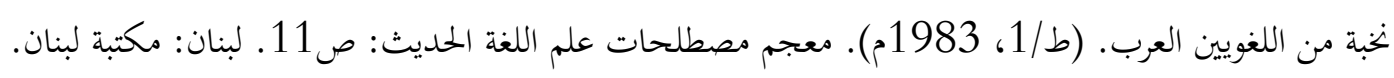

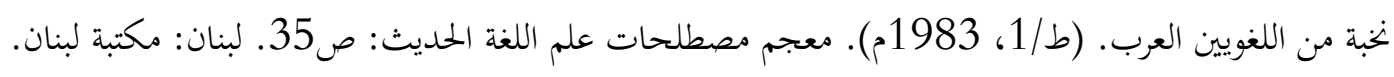

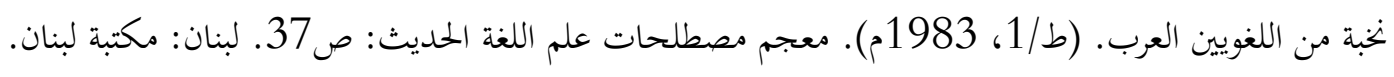

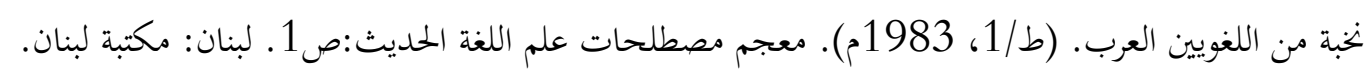

